\title{
Testing hypotheses of trophic level interactions: a boreal forest ecosystem
}

\author{
A. R. E. Sinclair, C. J. Krebs, J. M. Fryxell, R. Turkington, S. Boutin, R. Boonstra, P. Seccombe-Hett, \\ P. Lundberg and L. Oksanen
}

\begin{abstract}
Sinclair, A. R. E., Krebs, C. J., Fryxell, J. M., Turkington, R., Boutin, S., Boonstra, R., Seccombe-Hett, P., Lundberg, P. and Oksanen, L. 2000. Testing hypotheses of trophic level interactions: a boreal forest ecosystem. - Oikos 89: 313-328.
\end{abstract}

\begin{abstract}
Models of community organization involve variations of the top-down (predator control) or bottom-up (nutrient limitation) hypotheses. Verbal models, however, can be interpreted in different ways leading to confusion. Therefore, we predict from first principles the range of possible trophic level interactions, and define mathematically the instantaneous effects of experimental perturbations. Some of these interactions are logically and biologically unfeasible. The remaining set of 27 feasible models is based on an initial assumption, for simplicity, of linear interactions between trophic levels. Many more complex and non-linear models are logically feasible but, for parsimony, simple ones are tested first. We use an experiment in the boreal forest of Canada to test predictions of instantaneous changes to trophic levels and distinguish between competing models. Seven different perturbations systematically removed each trophic level or, for some levels, supplemented them. The predictions resulting from the perturbations were concerned with the direction of change in biomass in the other levels. The direct effects of each perturbation produced strong top-down and bottom-up changes in biomass. At both the vegetation and herbivore levels top-down was stronger than bottom-up despite some compensatory growth stimulated by herbivory. The combination of experiments produced results consistent with two-way (reciprocal) interactions at each level. Indirect effects on one or two levels removed from the perturbation were either very weak or undetectable. Top-down effects were strong when direct but attenuated quickly. Bottom-up effects were less strong but persisted as indirect effects to higher levels. Although the 'pure reciprocal' model best fits our results for the boreal forest system different models may apply to different ecosystems around the world.
\end{abstract}

A. R. E. Sinclair, C. J. Krebs, R. Turkington and P. Seccombe-Hett, Centre for Biodiversity Research, 6270 University Boulevard, Univ. of British Columbia, Vancouver, BC, Canada V6T 1Z4 (sinclair@zoology.ubc.ca). - J. M. Fryxell, Dept of Zoology, Univ. of Guelph, Guelph, ON, Canada N1G 2W1. - S. Boutin, Dept of Biological Sciences, Univ. of Alberta, Edmonton, AB, Canada T6G 2E9. - R. Boonstra, Div. of Life Sciences, Scarborough Campus, Univ. of Toronto, Scarborough, ON Canada M1C 1A4. - P. Lundberg, Dept of Theoretical Ecology, Lund Univ., Ecology Building, SE-223 62 Lund, Sweden. - L. Oksanen, Dept of Ecological Botany, Univ. of Umeà, SE-901 87, Umeà, Sweden.

Studies of biological communities ask two main questions: (1) how are they structured, and (2) how do they function? These questions are relevant to conservation of both natural ecosystems and systems which have been subjected to change from human activities eutrophication of lakes, acid rain pollution of lakes and forests, clearcutting of forests, introduction of exotic species, and creation of protected areas as islands within human ecosystems are some examples. We need to identify the major parts that hold the system together, the direction and strength of their interactions, and the components that are most sensitive to change

Accepted 17 September 1999

Copyright (C) OIKOS 2000

ISSN 0030-1299

Printed in Ireland - all rights reserved 
so that we can use them as indicators for long-term monitoring.

Community dynamics have been analyzed both by comparative methods and by perturbation experiments. These empirical studies have tested models of community organization which involve variations of top-down (pure predator control) hypotheses, bottom-up (nutrient limitation) hypotheses and hypotheses including reciprocal interactions (control by predators that are dependent on the prey, see Menge 1992, Power 1992). Moreover, self-regulation has been proposed as a major factor in population regulation (Chitty 1960, Krebs 1978). These concepts and some related ones (e.g. donor control) have not always been rigorously defined. Consequently, it has been difficult to derive testable and generally acceptable predictions.

Bottom-up hypotheses assume that systems are regulated by nutrient flow from below (White 1978, 1984, 1993, Lampert 1985, Polis and Strong 1996). The underlying idea is that all organisms live in a passively harsh environment, where there is shortage of suitable resources (e.g. plant parts of sufficiently high quality, prey which are easy to catch), even if resources appear superficially to be abundant. Bottom-up hypotheses can also be regarded as biological null hypotheses, because plants are essential to the levels above, whereas the reverse need not be true. According to bottom-up hypotheses higher trophic levels have neither a regulating effect, nor any influence on productivity or overall biomass on the levels below them, although the standing crops of suitable resources can be depressed (Hawkins 1992, Hunter and Price 1992, Strong 1992). The relationship of herbivore biomass to primary productivity (Coe et al. 1976, McNaughton et al. 1989) is consistent with this view for terrestrial systems, but the data are open to different interpretations (Moen and Oksanen 1991). At least technically, bottom-up hypotheses require some form of self-regulation. Otherwise population densities at each trophic level would either decline towards zero or increase to infinity. The mechanism of self-regulation could be through negative behavioral interactions, as argued by Chitty (1960) and Krebs (1978). Even depletion of high quality plant products and vulnerable prey individuals is most easily modeled as self-regulation in differential equation systems with plant, herbivore and predator standing crops as state variables. In plants, self-regulation could occur as a consequence of accumulation of non-photosynthetic tissues (a common situation in habitats where light is limiting).

There are various top-down hypotheses with radically different implications on population regulation. According to the hypothesis of Menge and Sutherland (1976), predation pressure increases monotonically from the top of the food chain downwards, which implies that top predators can exploit basal organisms. Caughley and Lawton (1981) in turn argued that the strong reciprocal interaction exists between herbivores and plants, whereas predators and herbivores are involved in a bottom-up relationship. Their view has been supported by data from arid and arctic ecosystems (Batzli et al. 1980, Caughley and Gunn 1993).

A converse idea was presented by Hairston et al. (1960), who proposed that a tight, reciprocal interaction takes place between predators and herbivores. Consequently, herbivores only have a light impact on plants, which are either self-regulated or involved in a reciprocal interaction with mineral nutrients. Evidence for this hypothesis, focusing on terrestrial ecosystems, comes from small mammals (Moen et al. 1993), insects (Atlegrim 1989, Marquis and Whelan 1994) and large mammals (McLaren and Peterson 1994). In some systems, predators have alternative resources (marinebased or detritus-based prey) and thus have a pure top-down relationship with herbivores. In marine intertidal systems the sea otter (Enhydra lutris), sea urchins (Strongylocentrus spp.) and macroalgae food chain is a classic example of this type of interaction (Estes et al. 1989, Estes and Duggins 1995). Carpenter et al. (1985, see also Carpenter and Kitchell 1987, 1988, 1993) applied the same idea to an aquatic food chain with four trophic levels. Here, the tight, reciprocal interactions were between piscivores and planktivores and between zooplankters and phytoplankters, whereas interactions between planktivores and zooplankters were weak. All these ideas imply that removal of the effective top consumer (herbivores according to Caughley and his co-workers, primary carnivores according to Hairston et al. and secondary carnivores according to Carpenter and Kitchell) generates cascading impacts down to plants and nutrients.

The hypothesis of exploitation ecosystems, outlined by Fretwell (1977) and analyzed by Oksanen et al. (1981, see also Oksanen 1988, 1990, T. Oksanen 1990) implies that different hypotheses involving reciprocal interactions apply to different ecosystems. The Caughley-Lawton hypothesis is relevant for relatively unproductive terrestrial ecosystems, where moderate grazer densities suffice to deplete the vegetation (e.g. tundras, steppes and semideserts). The hypothesis of Hairston et al. applies to relatively productive terrestrial ecosystems (e.g. forests and their successional stages) and to relatively unproductive pelagic ecosystems. The CarpenterKitchell hypothesis applies to moderately productive pelagic ecosystems, whereas really eutrophic lakes collapse back to the three level structure of Hairston et al., due to competition between planktivores and juvenile piscivores (Spencer and King 1984, Persson et al. 1988, 1992)

An hypothesis combining reciprocal and bottom-up features was proposed by McQueen et al. (1986, 1989, see also Benndorf and Horn 1985, Pace and Funke 1991) for aquatic systems. They propose that biomass is regulated from below by nutrient availability but this 
effect is strongest at the plant level and becomes weaker at progressively higher levels. Conversely, at the top of the food web, top-down interactions are strong but these effects weaken with every step down the food chain. In conjunction with this idea are a number of others which suggest that if the feeding efficiency of predators is reduced by interference, territoriality, or prey refuges then predator control of lower levels is attenuated more rapidly through the chain than if efficiency was not impaired. Consequently, bottom-up effects are seen at lower trophic levels (Power 1984, Arditi and Ginsburg 1989, Arditi et al. 1991, Hanski 1991, Leibold 1996).

The great number of different hypotheses and variants of them illustrated in the above discussion has generated confusion. First, it is not always realized that different hypotheses operate on different logical levels. For instance, the models of Oksanen et al. (1981) and Persson et al. (1988) make predictions on the ranges of applicability of other models, and should not be included in lists of elementary models. Secondly, all models with reciprocal interactions predict that perturbations lead to transient dynamics, where the initial rates of change depend on intrinsic growth rates at different trophic levels. The magnitudes of initial responses are, thus, not reliable indicators of the degrees of top-down and bottom-up control at equilibrium (see Yodzis 1988, Wootton 1994a, b).

In this paper we have two objectives. First, we derive from first principles the range of possible trophic level interactions and use these models to predict the instantaneous effects. Some of these interactions turn out to be unfeasible. The remaining set of feasible models may represent different ecosystems in the world. Secondly, we use an experiment in the boreal forest of Canada to illustrate how predictions concerning the responses of different trophic levels to various perturbations can distinguish between competing models. This experiment was a large-scale perturbation of the forest ecosystem initiated in 1986 to analyze the trophic interactions of the vertebrate food web, and it lasted ten years. The aim was to deduce how the major components of different trophic levels affect each other (Krebs et al. 1992, 1995, Boutin et al. 1995, Turkington et al. 1998).

\section{General models for trophic level interactions}

Operationally we detect the effects of one trophic level on another by whether the biomass of the latter changes (Power 1992) when the former is moderately perturbed from stable conditions but before new equilibria are established. We say that one trophic level 'limits' another if changes in one trophic level are associated with changes in the biomass of the adjacent level. There are, of course, a wide variety of ways in which one could link the elements of any food web. In the interests of simplicity, we have constructed linear systems that are feasible in a biological sense. Moreover, we limit ourselves to models with four trophic levels and without direct links between carnivores and plants or herbivores and nutrient pool. As a template we used equations of the following form:

$$
N \uparrow \leftrightarrow V \uparrow \leftrightarrow H \uparrow \leftrightarrow P \uparrow
$$

where $N$ denotes nutrient concentration, $V$ vegetation biomass (or primary producers), $H$ herbivore biomass (primary consumers), and $P$ carnivore biomass (secondary consumers). The arrows denote community matrix coefficients. A rightward arrow implies that an increase in resource density increases the rate of change of biomass of the adjacent consumer level at conditions near equilibrium to avoid non-linear effects. A leftward arrow implies that an increase in consumer density decreases the rate of change of the adjacent resource, and a vertical double arrow implies that a given trophic level has a density-dependent effect on its own rate of growth. According to such a simplified view, there are, therefore, four different effects that could be experienced by a given trophic level: $\rightarrow, \leftarrow, \leftrightarrow$, or $\uparrow$.

Some of the food web structures one could think of would be biologically implausible. For example, a terminal trophic level that has no density-dependent feedback on its growth would grow infinitely:

$N \rightarrow V \rightarrow H \rightarrow P$

Accordingly, there must be a $\uparrow$ effect at the end of each plausible chain or else $a \leftarrow$ link between the penultimate and terminal levels. Therefore, for logical reasons we have assumed that there must be some feedback on each level, and at least the potential for intratrophic level competition (i.e. there is always a vertical arrow at each level implied in our models). These restrictions reduce the large number of theoretical combinations of arrows to 27 biologically plausible models (Table 1), all of which have sufficient negative feedback to prevent unbounded growth.

To provide algebraic expressions for the 27 plausible food web structures, we start with the simplest (linear) density-dependent relationships in keeping with our minimalist objectives. For illustrative purposes, consider a system with purely bottom-up interactions (Model 1 in Table 1). A right arrow implies that increased plant biomass has no effect on the rate of change of plants but increases the rate of change of herbivores. Similarly, a right arrow implies that increased herbivore biomass has no effect on the rate of change of herbivores but increases the rate of change of carnivore biomass, and there is no converse effect of carnivores on herbivores. Therefore, a minimal model for all four levels might be 
$\frac{\mathrm{d} N}{\mathrm{~d} t}=r_{0}-a_{00} N$

$\frac{\mathrm{d} V}{\mathrm{~d} t}=a_{10} N V-a_{11} V^{2}$

$\frac{\mathrm{d} H}{\mathrm{~d} t}=a_{21} V H-a_{22} H^{2}$

$\frac{\mathrm{d} P}{\mathrm{~d} t}=a_{32} H P-a_{33} P^{2}$

where $r_{i}$ is the per capita rate of increase of trophic level $i$ and $a_{i j}$ is the community matrix coefficient for trophic level $j$ acting on trophic level $i$. Biologically this type of model would apply where herbivores feed only on senescent plants or non-growing plant tissues (as do wildebeest (Connochaetes taurinus), for example, in the dry season (Sinclair et al. 1985)) or predators feed on parts of herbivores in a way that does not affect the host.
In contrast, consider a purely top-down system (Model 5 in Table 1):

$\frac{\mathrm{d} N}{\mathrm{~d} t}=r_{0}-a_{00} N-a_{01} N V$
$\frac{\mathrm{d} V}{\mathrm{~d} t}=r_{1} V-a_{12} V H-a_{11} V^{2}$
$\frac{\mathrm{d} H}{\mathrm{~d} t}=r_{2} H-a_{23} H P-a_{22} H^{2}$

$\frac{\mathrm{d} P}{\mathrm{~d} t}=r_{3} P-a_{33} P^{2}$

Such a situation implies that herbivore growth, for example, is limited by something other than food even though herbivores do consume plants. One might visualize a pasture stocked with sheep that are fed a supplement by the farmer. The higher the stocking density, the shorter the height of the pasture, even though sheep fitness is little affected by plant biomass.

Table 1. Models for instantaneous change at each trophic level. We assume self limitation where there is no left arrow affecting a trophic level. A left arrow indicates that one level is changed by that above, a right arrow indicates that one level is changed by that below, a two-way arrow indicates that two levels affect each other. "Dilution" means that a level is influenced by both lower and higher levels, whereas "dominant" implies that a level affects both lower and higher levels. Nutrients = nutrient pool; Veg. $=$ vegetation biomass; Herbiv. $=$ herbivore biomass; Pred. $=$ predator biomass.

\begin{tabular}{|c|c|c|c|c|c|}
\hline & Model & Nutrients & Veg. & Herbiv. & Pred. \\
\hline \multicolumn{6}{|l|}{ Largely bottom-up } \\
\hline Pure bottom-up & 1 & & $\rightarrow$ & $\rightarrow$ & $\rightarrow$ \\
\hline Bottom-up, Nutrient reciprocal & 2 & & $\leftrightarrow$ & $\rightarrow$ & $\rightarrow$ \\
\hline Bottom-up, Vegetation reciprocal & 3 & & $\rightarrow$ & $\leftrightarrow$ & $\rightarrow$ \\
\hline Bottom-up, Herbivore reciprocal & 4 & & $\rightarrow$ & $\rightarrow$ & $\leftrightarrow$ \\
\hline \multicolumn{6}{|l|}{ Largely top-down } \\
\hline Pure top-down & 5 & & $\leftarrow$ & $\leftarrow$ & $\leftarrow$ \\
\hline Top-down, Nutrient reciprocal & 6 & & $\leftrightarrow$ & $\leftarrow$ & $\leftarrow$ \\
\hline Top-down, Vegetation reciprocal & 7 & & $\leftarrow$ & $\leftrightarrow$ & $\leftarrow$ \\
\hline Top-down, Herbivore reciprocal & 8 & & $\leftarrow$ & $\leftarrow$ & $\leftrightarrow$ \\
\hline \multicolumn{6}{|l|}{ Herbivore dominant } \\
\hline Herbivore dominant & 9 & & $\leftarrow$ & $\leftarrow$ & $\rightarrow$ \\
\hline Herbivore dominant, Vegetation dilution & 10 & & $\rightarrow$ & $\leftarrow$ & $\rightarrow$ \\
\hline Herbivore dominant, Nutrient reciprocal & 11 & & $\leftrightarrow$ & $\leftarrow$ & $\rightarrow$ \\
\hline Herbivore dominant, Predator reciprocal & 12 & & $\rightarrow$ & $\leftarrow$ & $\leftrightarrow$ \\
\hline Herbivore-Vegetation codominant & 13 & & $\leftarrow$ & $\leftrightarrow$ & $\rightarrow$ \\
\hline \multicolumn{6}{|l|}{ Vegetation dominant } \\
\hline Vegetation dominant & 14 & & $\leftarrow$ & $\rightarrow$ & $\rightarrow$ \\
\hline Vegetation dominant, Herbivore dilution & 15 & & $\leftarrow$ & $\rightarrow$ & $\leftarrow$ \\
\hline Vegetation dominant, Nutrient reciprocal & 16 & & $\leftrightarrow$ & $\rightarrow$ & $\leftarrow$ \\
\hline Vegetation dominant, Predator reciprocal & 17 & & $\leftarrow$ & $\rightarrow$ & $\leftrightarrow$ \\
\hline \multicolumn{6}{|l|}{ Largely dilution } \\
\hline Herbivore dilution & 18 & & $\rightarrow$ & $\rightarrow$ & $\leftarrow$ \\
\hline Vegetation dilution & 19 & & $\rightarrow$ & $\leftarrow$ & $\leftarrow$ \\
\hline Herbivore-Vegetation joint dilution & 20 & & $\rightarrow$ & $\leftrightarrow$ & $\leftarrow$ \\
\hline \multicolumn{6}{|l|}{ Largely reciprocal } \\
\hline Reciprocal, Herbivore bottom-up & 21 & & $\leftrightarrow$ & $\leftrightarrow$ & $\rightarrow$ \\
\hline Reciprocal, Predator top-down & 22 & & $\leftrightarrow$ & $\leftrightarrow$ & $\leftarrow$ \\
\hline Reciprocal, Nutrient bottom-up & 23 & & $\rightarrow$ & $\leftrightarrow$ & $\leftrightarrow$ \\
\hline Reciprocal, Vegetation top-down & 24 & & $\leftarrow$ & $\leftrightarrow$ & $\leftrightarrow$ \\
\hline Reciprocal, Vegetation bottom-up & 25 & & $\leftrightarrow$ & $\rightarrow$ & $\leftrightarrow$ \\
\hline Reciprocal, Herbivore top-down & 26 & & $\leftrightarrow$ & $\leftarrow$ & $\leftrightarrow$ \\
\hline $\begin{array}{l}\text { Pure reciprocal } \\
\text { Put }\end{array}$ & 27 & & $\leftrightarrow$ & $\leftrightarrow$ & $\leftrightarrow$ \\
\hline
\end{tabular}


A double headed horizontal arrow between plants and herbivores implies that herbivores respond to plant abundance and plants in turn respond to herbivore abundance, i.e. forming a 'laissez-faire' relationship (Caughley 1976). This might be denoted by Pure Reciprocal Model 27 in Table 1:

$\frac{\mathrm{d} N}{\mathrm{~d} t}=r_{0}-a_{00} N-a_{01} N V$

$\frac{\mathrm{d} V}{\mathrm{~d} t}=a_{10} N V-a_{12} V H-a_{11} V^{2}$

$\frac{\mathrm{d} H}{\mathrm{~d} t}=a_{21} V H-a_{23} H P-a_{22} H^{2}$

$\frac{\mathrm{d} P}{\mathrm{~d} t}=a_{32} H P-a_{33} P^{2}$

Similar lines of reasoning can be used to construct minimalist algebraic representations for the 27 feasible food webs under consideration, all of which we have verified numerically to produce sustainable communities. In all of these cases we have assumed a constant influx of nutrients that decays at a rate proportional to nutrient concentration from soil nutrient pools.

A number of equally plausible predictions arise regarding press perturbations of community elements (i.e. continuous removals of herbivores or predators) or changes in process rates, such as fertilization to enhance nutrient loading. We now explore these in the context of experiments in the boreal forest.

\section{Experimental perturbations of the boreal forest}

We tested the predictions from the 27 models by an experimental perturbation of the boreal forest food web (Krebs et al. 1995). In this experiment, different trophic levels were being perturbed and the subsequent effects on the biomass, productivity or activity of other levels were measured. The system is characterized at the plant level by grasses and herbaceous dicots, woody shrubs (Salix, Betula) and white spruce (Picea glauca); at the herbivore level by the dominant snowshoe hare (Lepus americanus) which exhibits a 10 -year cycle of numbers, and by ground squirrels (Spermophilus parryii), red squirrels (Tamiasciurus hudsonicus) and various vole species (Clethrionomys, Microtus); and at the predator level by carnivores such as lynx (Lynx canadensis) and coyote (Canis latrans) and various raptors, notably the great horned owl (Bubo virginianus).

\section{Direct and indirect effects}

Predictions from the models on the effects of the perturbations are through the direction of change in biomass relative to control areas. The predicted changes in biomass are indicated in Table 2 as an increase, decrease or no change. However, where two perturbations are applied simultaneously, both acting in the same direction, an additional prediction can be made on the magnitude of change relative to either single perturbation.

We measure two types of response, biomass change and productivity change. A direct effect occurs in the biomass or productivity at the next trophic level, an indirect effect at one or more levels removed. These indirect effects are a subset of 'interaction-chain indirect effects' (Wootton 1993, 1994a, b, c, Billick and Case 1994, Menge 1997) in that they are linear on the food chain. They do not include interactions such as apparent competition (Holt 1977) or indirect mutualism (Dungan 1987) that involve interactions between species within a trophic level, or interaction modifications such as predation risk (Boonstra et al. 1998). We address these in a future publication.

\section{The experiments}

\section{(1) Application of fertilizer}

Fertilizer was applied from the air to two $1-\mathrm{km}^{2}$ blocks of forest. This should increase the soil nutrient pool $(N)$. Models which suggest that plants are responsive to the nutrient pool (i.e. those with right or double arrows between $N$ and $V$ ) predict increases in biomass of higher trophic levels to varying lengths of the food chain (18 of the models). Models with a left arrow only ( 9 models) predict that plant biomass is not limited by nutrients and should not respond to fertilizer inputs. However, productivity of plants and consumption by herbivores could increase. Similarly, productivity of herbivores and consumption by predators could increase.

\section{(2) Food addition}

Commercial rabbit chow was applied ad lib to two areas of 40 ha. This food is eaten readily by hares and ground squirrels. The treatment had the effect of artificially increasing the food supply for herbivores independently of the natural food and, therefore, increasing the herbivore level independently of the vegetation level. Models that propose herbivores respond to food supply (18 models) predict an increase in herbivores and in half of these a subsequent decrease in natural food, i.e. there is a double arrow. Twelve of these 
Table 2. Predictions of the direction of change in biomass at each of the trophic levels from each of the seven experimental treatments according to the 27 models. Experiment $1=$ Fertilizer addition, $2=$ Food addition, $3=$ Predator exclosure, $4=$ Predator exclosure + food addition, $5=$ Hare exclosure, $6=$ Hare exclosure + fertilizer, $7=$ vegetation exclosure. $+=$ biomass increase, $++=$ double effect on biomass of two treatments, $-=$ biomass decrease, $0=$ no change, and $?=$ unpredictable. Since the predator fence eliminates mammalian predators no predictions are made for that level in the fence treatments. Similarly, the hare exclosures preclude predictions for the herbivore and predator levels, and vegetation removal precludes predictions for all three higher levels.

\begin{tabular}{|c|c|c|c|c|c|c|c|c|c|c|c|c|c|c|c|c|c|c|c|}
\hline \multirow[t]{2}{*}{ Model } & \multicolumn{4}{|c|}{ Experiment 1} & \multicolumn{4}{|l|}{2} & \multicolumn{3}{|l|}{3} & \multicolumn{3}{|l|}{4} & \multicolumn{2}{|l|}{5} & \multicolumn{2}{|l|}{6} & \multirow{2}{*}{$\frac{7}{N}$} \\
\hline & $N$ & $V$ & $H$ & $P$ & $N$ & $V$ & $H$ & $P$ & $N$ & $V$ & $H$ & $N$ & $V$ & $H$ & $N$ & $V$ & $N$ & $V$ & \\
\hline 1 & + & + & + & + & 0 & 0 & + & + & 0 & 0 & 0 & 0 & 0 & + & 0 & 0 & + & + & 0 \\
\hline 2 & + & + & + & + & 0 & 0 & + & + & 0 & 0 & 0 & 0 & 0 & + & 0 & 0 & $?$ & + & + \\
\hline 3 & + & + & + & + & 0 & - & + & + & 0 & 0 & 0 & 0 & - & + & 0 & + & + & ++ & 0 \\
\hline 4 & + & + & + & + & 0 & 0 & + & + & 0 & 0 & + & 0 & 0 & ++ & 0 & 0 & + & + & 0 \\
\hline 5 & + & 0 & 0 & 0 & 0 & 0 & 0 & 0 & + & - & + & + & - & + & - & + & $?$ & + & + \\
\hline 6 & + & + & 0 & 0 & 0 & 0 & 0 & 0 & + & - & + & + & - & + & - & + & $?$ & ++ & + \\
\hline 7 & + & 0 & 0 & 0 & + & - & + & 0 & + & - & + & ++ & -- & ++ & - & + & $?$ & + & + \\
\hline 8 & + & 0 & 0 & 0 & 0 & 0 & 0 & 0 & + & - & + & + & - & + & - & + & $?$ & + & + \\
\hline 9 & + & 0 & 0 & 0 & 0 & 0 & 0 & 0 & 0 & 0 & 0 & 0 & 0 & 0 & - & + & $?$ & + & + \\
\hline 10 & + & + & 0 & 0 & 0 & 0 & 0 & 0 & 0 & 0 & 0 & 0 & 0 & 0 & 0 & + & + & ++ & 0 \\
\hline 11 & + & + & 0 & 0 & 0 & 0 & 0 & 0 & 0 & 0 & 0 & 0 & 0 & 0 & - & + & $?$ & ++ & + \\
\hline 12 & + & + & 0 & 0 & 0 & 0 & 0 & 0 & 0 & - & + & 0 & - & + & 0 & + & + & ++ & 0 \\
\hline 13 & + & 0 & 0 & 0 & + & - & + & + & 0 & 0 & 0 & + & - & + & - & + & $?$ & + & + \\
\hline 14 & + & 0 & 0 & 0 & 0 & 0 & + & + & 0 & 0 & 0 & 0 & 0 & + & 0 & 0 & + & 0 & + \\
\hline 15 & + & 0 & 0 & 0 & 0 & 0 & + & 0 & 0 & 0 & + & 0 & 0 & ++ & 0 & 0 & + & 0 & + \\
\hline 16 & + & + & + & 0 & 0 & 0 & + & 0 & 0 & 0 & + & 0 & 0 & ++ & 0 & 0 & $?$ & + & + \\
\hline 17 & + & 0 & 0 & 0 & 0 & 0 & + & + & 0 & 0 & + & 0 & 0 & ++ & 0 & 0 & + & 0 & + \\
\hline 18 & + & + & + & 0 & 0 & 0 & + & 0 & 0 & 0 & + & 0 & 0 & ++ & 0 & 0 & + & + & 0 \\
\hline 19 & + & + & 0 & 0 & 0 & 0 & 0 & 0 & 0 & - & + & 0 & - & + & 0 & + & + & ++ & 0 \\
\hline 20 & + & + & + & 0 & 0 & - & + & 0 & 0 & - & + & 0 & -- & ++ & 0 & + & + & ++ & 0 \\
\hline 21 & + & + & + & + & + & - & + & + & 0 & 0 & 0 & + & - & + & - & + & $?$ & ++ & + \\
\hline 22 & + & + & + & 0 & + & - & + & 0 & + & - & + & ++ & -- & ++ & - & + & $?$ & ++ & + \\
\hline 23 & + & + & + & + & 0 & - & + & + & 0 & - & + & 0 & -- & ++ & 0 & + & + & ++ & 0 \\
\hline 24 & + & 0 & 0 & 0 & + & - & + & + & + & - & + & ++ & -- & ++ & - & + & $?$ & + & + \\
\hline 25 & + & + & + & + & 0 & 0 & + & + & 0 & 0 & + & 0 & 0 & ++ & 0 & 0 & ? & + & + \\
\hline 26 & + & + & 0 & 0 & 0 & 0 & 0 & 0 & + & - & + & + & - & + & - & + & $?$ & ++ & + \\
\hline 27 & + & + & + & + & + & - & + & + & + & - & + & ++ & -- & ++ & - & + & ? & ++ & + \\
\hline
\end{tabular}

models also predict that predators should increase. The remaining nine models assume that herbivores are not limited by food supply and so no trophic level responds to food addition.

\section{(3) The exclusion of carnivores}

Carnivores were excluded from a $1-\mathrm{km}^{2}$ area by wire fencing. This fence is permeable to hares and squirrels through small holes in the fence. For our purposes it reduces the predator trophic level, and provides the prediction of a cascading effect on successively lower levels in models that are responsive to the higher trophic level.

\section{(4) The exclusion of carnivores and the addition of rabbit chow}

Carnivores were excluded from a $1-\mathrm{km}^{2}$ area by wire fencing, and ad lib rabbit chow was provided for the herbivores. The removal of mammalian predators is predicted to increase herbivores in the 18 models that respond to the predator level. In addition, for the 12 models where herbivores are also responsive to their food supply we predict an additional increase in herbivore biomass relative to the herbivore increase predicted from experiment (3). Consequently, there should be double the effect on other trophic levels. The remaining models where herbivores do not respond to food supply predict changes in herbivore biomass similar to that in experiment (3).

\section{(5) The exclusion of hares}

Hares were the dominant herbivore biomass in the system and they were excluded by fencing a 4-ha area. Exclusion had the effect of removing the top two trophic levels. The predictions are that vegetation biomass should increase in 18 models and soil nutrients decrease in a subset of 12 of these.

\section{(6) The exclusion of hares and the addition of fertilizer}

This experiment was similar to (5) but with the addition of fertilizer as in (1) above. The two perturbations are 
predicted to have opposite effects on soil nutrients fertilizer adds nutrients but removal of hares should result in less nutrients. Since the outcome could be any value depending on absolute amounts of inputs and outputs no qualitative prediction for soil nutrients can be made. However, for vegetation biomass one can predict two alternative responses. In models where plants respond to nutrient levels there should be a greater increase in plant biomass relative to experiment (5). In contrast, the other models predict no difference in plant biomass changes between experiments (5) and (6).

\section{(7) The removal of vegetation}

Soil nutrient levels were measured in plots where vegetation was removed and compared with an equal number of immediately adjacent control plots with intact vegetation. Soil nutrients should increase in plots where the vegetation has been removed in those models predicting that nutrients respond to plant uptake.

With these experiments 21 models make unique sets of predictions. There are also three pairs of unique sets (5\& 8, $12 \& 19$ and $6 \& 26$, Table 2).

\section{Methods}

\section{Soil nitrogen}

Fertilizer was applied by air once each year in the spring (May) for the years 1987-1994. In 1995, ten soil samples were collected at sites on experimental treatments and immediately adjacent to them as controls (P. Seccombe-Hett and R. Turkington unpubl.). The treatment grids sampled were fertilizer, food addition, predator exclosure plus food addition, and hare exclosure. In 1996 soils were sampled inside ( $n=100$ samples) and outside the hare exclosure. Also outside this exclosure, vegetation was removed from 156 plots and soil samples were compared with 156 plots with vegetation left intact. Vegetation was killed by using Roundup ${ }^{\mathrm{TM}}$ and left in situ. The edges of all plots were cut to a spade-depth to kill roots and so reduce the movement of nutrients into, or out from, the plot ( $\mathrm{P}$. Seccombe-Hett and R. Turkington unpubl.). In 1995, soils were sent to Peace Growers' lab in Fort St. John, BC and in 1996 to Pacific Soil Analysis in Richmond, $\mathrm{BC}$ for analysis of nitrate nitrogen.

\section{Vegetation}

Details of methods are presented in Krebs et al. (1992, 1995) and Turkington et al. (1998). Mammalian herbivores have little influence on biomass of herbaceous vegetation during the summer (John and Turkington 1995). Winter food supply is more likely to be limiting to mammalian herbivores. Winter food plants for snowshoe hares are bog birch (Betula glandulosa) and grey willow (Salix glauca). Twigs $<5 \mathrm{~mm}$ diameter were the main food. Biomass of these twigs was obtained from quadrats $(10 \mathrm{~m} \times 0.2 \mathrm{~m})$ randomly placed on controls, fertilizer, predator exclosure + food addition and hare exclosure. All woody shrub species in the quadrats were clipped and 5-mm twigs clipped and separated from the larger stems. Twigs were dried and weighed.

Growth of these twigs was measured from a sample of larger stems collected at the end of each growing season. Growth is presented as the percent of current annual growth $(\% \mathrm{CAG})$ in the total dry weight of $5-\mathrm{mm}$ twig. Thus, twigs were clipped at the 5-mm diameter, and these divided into CAG and the rest. Approximately 200 twigs of each species were measured on each treatment. Birch, however, did not occur in the hare exclosure.

The percentage of 5-mm twigs that were browsed over the winter was obtained from labeled twigs. About 200 twigs of each species labeled in the autumn were scored for herbivory in the spring on each treatment.

The "net effect" on plant biomass combines the herbivory in one winter and the growth in the subsequent summer. It measures the degree to which an increase in growth rate $\left(g_{i}\right)$ of plant species $i$ in year $y$ compensates for the biomass loss to herbivory $\left(h_{i}\right)$ in the previous winter. The net effect $C_{i y}$ is given by

$C_{i y}=\left(1-h_{i}\right)\left(1+g_{i}\right)$

If $C_{i y}=1$ there is complete compensation and no change in biomass, $<1$ a net loss in biomass and $>1$ an increase in biomass by over-compensation.

\section{Herbivore biomass}

The dominant herbivores in summer are the snowshoe hare and arctic ground squirrel with red squirrel a minor third species. In winter the snowshoe hare is effectively the only herbivore. All species were enumerated by live-trapping and the details are given in Boutin et al. (1995).

\section{Predator activity}

For practical response we could monitor only the main carnivore species, lynx and coyote, and we could not measure the biomass of these species for each experiment independently. Therefore, we used an index of their total response (functional $\times$ numerical) by counting the number of tracks in winter. Following each 
Table 3. Combined grey willow and bog birch biomass of $5-\mathrm{mm}$ twigs $\left(\mathrm{g} \mathrm{m}^{-2}\right)$ on $2-\mathrm{m}^{2}$ quadrats for 1992, the year following maximum browsing, and as a mean for the ten years 1987-1996 (1990-1996 for the predator exclosure plus food addition). To make comparisons across grids values were standardized to 100 in 1990.

\begin{tabular}{lrrr}
\hline Site & Year & Peak & 10-year mean \\
\hline Control & 1991 & 133.4 & 94.5 \\
& 1992 & 113.6 & 94.5 \\
Fertilizer & 1992 & 149.6 & 133.7 \\
Predator exclosure + & 1991 & 14.3 & 32.9 \\
$\quad$ Food addition & 1992 & 6.9 & 32.9 \\
Hare exclosure & 1992 & 101.9 & 78 \\
\hline
\end{tabular}

snowfall, the perimeters of the experiments were surveyed. The number of fresh tracks of each species crossing the perimeter in the previous day was scored and averaged for that winter. The relevant sites where predator activity was measured are controls, fertilizer and food addition.
Table 6. Total herbivore biomass $\left(\mathrm{kg} \mathrm{ha}^{-1}\right)$ on the experimental sites in the year of peak biomass and as a mean over 1987-1996. Hare peak was in 1990.

\begin{tabular}{lrrl}
\hline Site & Year & Peak & 10-year mean \\
\hline Control & 1990 & 3.34 & 2.48 \\
& 1991 & 2.83 & \\
Fertilizer & 1990 & 4.22 & 2.73 \\
Food addition & 1991 & 13.34 & 6.52 \\
Predator exclosure & 1991 & 4.49 & 3.23 \\
Predator exclosure + & 1991 & 10.59 & 11.30 \\
$\quad$ Food addition & & & \\
\hline
\end{tabular}

\section{Results}

Results for each of the experiments are presented in Tables 3-7. These are compared with values from the control sites. For the vegetation removal experiment controls were immediately adjacent to the removal plots rather than on the control grids. Indirect effects are

Table 4. Percent current annual growth (\%CAG) of 5-mm twigs of grey willow and bog birch in the peak year and as the mean over 1988-1995. CAG = new growth/total twig dry mass. 95\% CR =95\% confidence range. Hare peak was 1990.

\begin{tabular}{lccc}
\hline Site & Year & Peak $(95 \% \mathrm{CR})$ & Mean $(95 \% \mathrm{CR})$ \\
\hline Willow & 1991 & $12.43(11.70-13.2)$ & $15.37(15.07-15.67)$ \\
Control & 1992 & $11.98(11.22-12.78)$ & $15.37(15.07-15.67)$ \\
Fertilizer & 1992 & $21.34(20.00-22.68)$ & $19.95(19.48-20.42)$ \\
Food addition & 1992 & $31.56(28.22-35.31)$ & $22.72(21.81-23.63)$ \\
Predator exclosure & 1992 & $16.11(14.82-17.40)$ & $16.77(16.22-17.32)$ \\
Predator exclosure+Food addition & 1992 & $26.68(24.46-29.09)$ & $23.22(22.42-24.02)$ \\
Hare exclosure & 1991 & $11.27(9.97-12.73)$ & $14.82(14.26-15.38)$ \\
& 1992 & $14.84(13.17-16.71)$ & $14.82(14.26-15.38)$ \\
Hare exclosure+Fertilizer & 1992 & $16.91(15.13-18.69)$ & $20.22(19.75-20.69)$ \\
Birch & & & \\
Control & 1992 & $23.88(22.13-25.70)$ & $16.24(15.85-16.63)$ \\
Fertilizer & 1992 & $31.91(30.50-33.32)$ & $20.56(20.10-21.02)$ \\
Food addition & 1992 & $27.16(25.23-29.16)$ & $12.08(11.28-12.88)$ \\
Predator exclosure & 1992 & $21.11(19.41-22.89)$ & $17.54(17.02-18.06)$ \\
Predator exclosure +Food addition & 1992 & $36.55(34.02-39.17)$ & $25.24(24.44-26.04)$ \\
Hare exclosure+Fertilizer & 1992 & $19.94(18.54-21.34)$ & $20.41(19.69-21.13)$ \\
\hline
\end{tabular}

Table 5. The percentage of 5-mm twigs of willow and birch that were completely browsed in the peak winter 1990-1991. The net effect is the net biomass in September 1991 relative to that in September 1990 as a result of browsing followed by growth in summer 1991 .

\begin{tabular}{|c|c|c|c|c|}
\hline \multirow[t]{2}{*}{ Site } & \multicolumn{2}{|l|}{ Willow } & \multicolumn{2}{|l|}{ Birch } \\
\hline & $\%$ Browse & Net effect & $\%$ Browse & Net effect \\
\hline Control & 12.9 & 0.98 & 85.7 & 0.16 \\
\hline Fertilizer & 34.9 & 0.78 & 61.7 & 0.49 \\
\hline Food addition & 47.1 & 0.63 & 57.3 & 0.51 \\
\hline Predator exclosure & 10.8 & 1.01 & 51.5 & 0.56 \\
\hline Predator exclosure + Food addition & 62.8 & 0.44 & 88.2 & 0.15 \\
\hline Hare exclosure & 0 & 1.13 & - & - \\
\hline Hare exclosure + Fertilizer & 0 & 1.18 & 0 & 1.23 \\
\hline
\end{tabular}


seen in the next but one level from the perturbation and double indirect effects are seen in two trophic levels removed from the perturbation. To measure direct and indirect effects data from different years were used. Peak herbivore biomass occurred in 1990. Both maximum browsing by herbivores on winter food and peak predator activity were observed in the winter of 1990 1991. The major decline of herbivore numbers took place in winter 1991-1992. Peak growth of winter food plants $(\% \mathrm{CAG})$ occurred in 1992, after browsing declined.

First we present the results for direct interactions (i.e. the response of the trophic level adjacent to that perturbed) and then we show the results for indirect interactions.

\section{Direct effects of trophic level perturbations}

\section{(1) Fertilizer addition}

The mean rate of fertilizer application over the years 1987-1994 was $150( \pm 30 \mathrm{SE}) \mathrm{kg} \mathrm{N}$ per hectare per year in the form of ammonium nitrate (Turkington et al. 1998). Measurement of nitrogen in the soil in midJune 1995 showed 40.3 ppm ( $\pm 9.795 \%$ CL) nitrate nitrogen compared with $0.97 \mathrm{ppm}( \pm 0.19 \mathrm{CL})$ in immediately adjacent control samples $(P<0.001)$.

In 1992, the year of peak vegetation biomass, addition of fertilizer produced biomass values of $149.6 \mathrm{~g}$ $\mathrm{m}^{-2}$ compared with $113.6 \mathrm{~g} \mathrm{~m}^{-2}$ on control sites for winter twigs (Table 3 ). Productivity was measured by $\%$ CAG in $5 \mathrm{~mm}$ twigs (Table 4). Productivity in woody plants increased in summer 1992, two years after peak herbivore biomass. For birch \%CAG was 31.91 ( \pm 1.41 CL) on fertilized grids compared with $23.88( \pm 1.8 \mathrm{CL})$ on controls. For willow \%CAG was $21.34( \pm 1.34 \mathrm{CL})$ on fertilized grids compared with $11.98( \pm 0.8 \mathrm{CL})$ in controls. Both species showed significant $(P<0.05)$ increases in growth on fertilizer areas relative to controls at the peak. Over the whole cycle growth on the fertilized grids was consistently above that on control grids (Table 4). Therefore, these figures are consistent with models showing direct bottom-up effects (Table 1).

Table 7. Mean snow track counts per day for lynx and coyote over the winter of peak hare numbers (1990-1991) and the mean over the eight winters 1988-1989 to 1995-1996 (95\% CL).

\begin{tabular}{llllll}
\hline Site & \multicolumn{2}{l}{ Lynx } & & \multicolumn{2}{l}{ Coyote } \\
\cline { 2 - 3 } \cline { 5 - 6 } \cline { 5 - 6 } & Peak & 8-year mean & & Peak & 8-year mean \\
\hline Control & 0.96 & $0.76(0.54)$ & & 0.50 & $0.50(0.36)$ \\
Fertilizer & 4.63 & $1.61(1.24)$ & & 1.75 & $0.45(0.44)$ \\
Food addition & 2.89 & $1.15(0.82)$ & & 5.00 & $1.51(1.08)$ \\
\hline
\end{tabular}

\section{(2) Addition of hare food}

On the food addition sites hares ate rabbit chow year round, and arctic ground squirrels ate it in summer. Rabbit chow had the effect of increasing the density of these herbivores. Thus, in spring 1991 at the peak, total herbivore biomass on these sites was $13.34 \mathrm{~kg} / \mathrm{ha}$ compared with $2.83 \mathrm{~kg} / \mathrm{ha}$ on the controls, a 5-fold increase. Averaged over the cycle these values were 6.52 and 2.48, respectively (Table 6).

The impact of hare feeding on winter food plants was measured by the percent of 5-mm twigs browsed. In winter 1990-1991 with peak herbivore biomass, 57.3\% of birch and $47.1 \%$ of willow twigs were browsed on food addition sites, compared with $85.7 \%$ of birch and $12.9 \%$ of willow twigs on controls (Table 5). Thus, higher hare density on this treatment resulted in higher browsing on willow, but not on birch.

Vegetation growth but not biomass was measured on these sites. The \%CAG of 5-mm twigs in 1992 was $31.56 \%$ for willow and $27.16 \%$ for birch on food addition sites compared with $11.98 \%$ for willow and $23.88 \%$ for birch on controls (Table 4). Thus, the higher browsing on willow resulted in a significant $(P<0.05)$ increase in growth on this treatment two years later.

The net effect of peak browsing and one season's subsequent growth showed that birch biomass in autumn 1991 was 0.51 that a year earlier and willow biomass was 0.63 that a year earlier. Thus, growth did not compensate for herbivory. However, because growth responded two years after peak browsing, the net effect in 1992 for birch biomass was 1.22 and for willow biomass it was 1.24 , indicating an increase in vegetation biomass despite herbivory.

In summary, the effect of increasing herbivore biomass was to decrease vegetation biomass and this decrease could not be compensated for by increased growth in the following year. However, once the herbivore biomass had declined two years later, then growth more than compensated for herbivory. These results are consistent with top-down effects.

Predator tracks crossing the perimeter of each experimental site were counted after each fresh snowfall and averaged as the number per day in each winter (Table 7). In winter 1991-1992 coyote tracks were 5.0/day on the food addition areas versus 1.50 /day on controls, and lynx tracks were 1.73 and 0.50 /day for the two areas respectively. Thus, mammalian predator activity increased by a factor of 3 on the food addition sites, consistent with bottom-up effects.

\section{(3) Predator exclosure}

Large carnivores such as lynx and coyote were excluded from the experimental site. Avian predators were inhibited in their hunting by nylon monofilament placed $2 \mathrm{~m}$ 
above ground at $20-\mathrm{cm}$ intervals in a small (10 ha) area. However, the inhibitory effect was minor for the whole site. Herbivore biomass in 1991 in the exclosure was 4.49 $\mathrm{kg} / \mathrm{ha}$ and on the controls was $2.83 \mathrm{~kg} / \mathrm{ha}$, respectively, indicating a small but consistent increase in herbivores in the exclosure by a factor of 1.6 (Table 6). This indicates a top-down effect of mammalian predators.

\section{(4) Predator exclosure and food addition}

On this experimental site, where both carnivores were excluded and rabbit chow was provided, herbivore biomass in 1991 was $10.59 \mathrm{~kg} / \mathrm{ha}$ compared with 13.34 on the food addition alone, $4.49 \mathrm{~kg} / \mathrm{ha}$ on the predator exclosure alone, and $2.83 \mathrm{~kg} / \mathrm{ha}$ on the controls. The mean value over the cycle for the double treatment was $11.30 \mathrm{~kg} / \mathrm{ha}$, showing a 4.5-fold increase over controls (2.48 kg/ha), a 3.5 fold increase over the predator exclosure alone $(3.23 \mathrm{~kg} / \mathrm{ha})$ and a 1.7 -fold increase over the food addition alone $(6.5 \mathrm{~kg} / \mathrm{ha})$ (Table 6).

Winter food plant biomass on the predator exclosure plus food addition treatment in 1991 following peak browsing was $14.3 \mathrm{~kg} /$ ha compared with $133.4 \mathrm{~kg} /$ ha on controls, a 9-fold decrease. Mean values over the cycle were $32.9 \mathrm{~kg} / \mathrm{ha}$ and $94.5 \mathrm{~kg} / \mathrm{ha}$ respectively, a 3-fold difference (Table 3 ). As a consequence of the very high herbivore biomass, herbivore browsing was severe in winter 1990-1991. Thus, $88.2 \%$ of birch twigs were browsed on the treatment compared with $85.7 \%$ on controls, and $62.8 \%$ of willow twigs on the treatment compared with $12.9 \%$ on the controls (Table 5).

Because browsing on birch was so high on control plots there was little room for the treatment to be higher. However, browsing of willow on the treatment was considerably higher than on controls. Consequently, in 1991 the net reduction of biomass in birch twigs was very large but did not differ between treatment and controls $(0.15$ of the biomass a year earlier on the treatment compared with 0.16 on controls). In contrast, net biomass of willow twigs declined to 0.44 of that a year earlier on the treatment compared with 0.98 on controls. Thus, willow biomass declined by a factor of 2.2 relative to controls (Table 5). Growth did not compensate for browsing in either species on this treatment.

In 1992 the treatment produced a $36.6 \%$ growth of birch twigs and $26.7 \%$ growth of willow twigs relative to $23.9 \%$ and $12.0 \%$, respectively, on controls. Growth of both species on this treatment was higher than that on the predator exclosure, and birch growth (but not willow) was also higher than that on the food addition (Table 4).

In summary, this double treatment can be compared not only with controls but also with the single treatments. The increase in herbivore density relative to the food addition alone indicates the top-down effect from removal of predators. Similarly, the decrease in plant biomass relative to controls indicates the top-down effect of herbivores. The increase in plant productivity was a response to herbivory but it was not sufficient to compensate for the loss of plant biomass.

\section{(5) Hare exclosure}

This treatment excluded the dominant herbivores, hares and moose (Alces alces) and the only herbivores in winter. Since moose were rare these potential impacts were all hare driven. Willow was the only winter food species in the exclosure. In 1992 biomass of 5-mm twigs was $101.9 \mathrm{~kg} / \mathrm{ha}$ in the exclosure compared with 113.6 $\mathrm{kg} /$ ha on the controls. When standardized to 100 in 1990 there was no difference in twig biomass between the exclosure and control in the period 1990-1996.

Growth of willow twigs in the hare exclosure did not follow the cycle as it did outside, but rather appeared to decline slightly over the eight years. In 1992 growth in the exclosure $(14.84 \%)$ did not differ markedly from willow on controls $(11.98 \%)$, and over the cycle mean growth was similar (14.82\% exclosure, $15.37 \%$ controls).

In 1991 the year of highest browsing impact, net biomass for the exclosure increased by a factor of 1.13 , compared with 0.98 on controls. Thus, the removal of herbivores allowed a net increase in willow twig biomass. Over the whole cycle, willow biomass showed a net increase in the exclosure by 1.15 , compared with 1.09 on controls.

\section{(6) Hare exclosure plus fertilizer}

Vegetation on this experimental plot was measured as the $\%$ CAG of 5-mm twigs (Table 4). In 1992, on this double treatment site, \%CAG of willows was $16.9 \%$ compared with $12.0 \%$ on controls. Over the cycle growth remained approximately constant and averaged 20.2\% compared with $15.4 \%$ on controls. For birch in 1992 $\%$ CAG was $19.9 \%$ on the exclosure compared with a maximum of $23.9 \%$ on controls. Over the cycle birch growth also showed no trend in the exclosure and averaged $20.4 \%$ compared with $16.2 \%$ on controls. These values all differed from each other at the $95 \% \mathrm{CL}$ but effects were small. However, willow showed increased growth in the exclosure relative to controls but birch did not.

In 1992 the growth rate $(\% \mathrm{CAG})$ on fertilizer plots (21.3\% for willow, $31.9 \%$ for birch) was significantly higher than that in the fertilized hare exclosure $(16.9 \%$ for willow, $19.9 \%$ for birch). Therefore, browsing by herbivores at peak densities on the fertilizer areas stimulated productivity of the vegetation.

However, because there was substantial browsing of twigs on the fertilizer plots the higher growth rates could 
not compensate sufficiently for the loss of biomass. Net biomass of willow twigs on fertilized grids decreased by a factor of 0.78 , and that of birch decreased by a factor of 0.49 in 1991 (Table 5). In contrast, on the fertilized exclosure net biomass of 5-mm willow twigs increased by a factor of 1.18 and that of birch increased by 1.23 , showing that protection from browsing allowed an increase of vegetation biomass while exposure to browsing caused a decrease by half or more.

Comparing the fertilized exclosure with the unfertilized exclosure over the cycle there was an increase in $\%$ CAG of willows (Table 4) indicating a bottom-up effect of fertilizer. However, during the year of peak regrowth (1992) both the \%CAG (Table 4) and the increase in net biomass of willows (Table 5) did not differ between the two treatments suggesting that fertilizer had little bottom-up effect compared with that of browsing. Therefore, hare removal rather than fertilizer was the predominant effect observed with this experiment when herbivores were abundant. In summary, top-down effects were observed both through the decrease in vegetation biomass and through an increase in subsequent vegetation productivity.

\section{(7) Vegetation removal}

In 1996 soils were sampled from 156 vegetation removal plots and 156 control sites with vegetation present immediately adjacent to them. The nitrate nitrogen value on the 156 removal plots was $6.58( \pm 0.41$ $95 \%$ C.L.) compared with $5.2( \pm 0.3495 \%$ C.L.) on the control plots. The removal plots were significantly $(P<$ 0.0001) higher in soil nitrogen compared with those with vegetation, indicating that herbaceous vegetation reduced the nitrogen content of soils.

\section{Indirect effects of trophic level perturbations}

\section{(1) Fertilizer addition}

Indirect effects of fertilizer addition would be experienced at the herbivore level. In 1990, the year of peak biomass, herbivores on fertilizer grids were $4.22 \mathrm{~kg} / \mathrm{ha}$, those on controls $3.34 \mathrm{~kg} / \mathrm{ha}$, a small but significant difference. Over all eight years there was no difference (fertilizer $2.73 \mathrm{~kg} / \mathrm{ha}$, control $2.48 \mathrm{~kg} / \mathrm{ha}$ ) (Table 6).

Double indirect effects would occur at the predator level. Predator tracks on fertilizer grids in the peak winter of 1990-1991 were 4.63/day for lynx and 1.75/ day for coyote compared with 0.96 /day and 0.50 /day, respectively, for controls (Table 7). Thus, both predator species patrolled fertilizer grids more than control areas in the peak year. Over the eight years there was no significant difference in mean track counts for either species between fertilizer and control grids. Thus, bottom-up indirect effects were observed at both higher levels of the food chain.

\section{(2) Food addition}

The indirect effect of increasing herbivore numbers on the food addition grids would be seen at the soil nutrient level. In 1995 soil nitrate nitrogen on the food addition was $2.7 \mathrm{ppm}$, that on controls was $3.3 \mathrm{ppm}$. The difference was not significant at $P=0.05$.

\section{(3) Predator exclosure}

Indirect effects would be observed at the vegetation level. In winter 1990-1991 browsing impact in the predator exclosure on birch was $51.5 \%$ versus $85.7 \%$ on controls, and on willow the values were $10.8 \%$ in exclosure and $12.9 \%$ on controls. Herbivory in the peak year, therefore, did not increase in the predator exclosure (Table 5). Furthermore, willow growth in the subsequent summer of 1991 completely compensated for this browsing in both exclosure and control (net change in biomass was 1.01 and 0.98 respectively). Birch growth, however, did not compensate for the higher browsing rate and biomass declined in 1991 on both exclosure (net change 0.56) and control (net change 0.16) (Table 5).

In 1992 willows had significantly higher growth in the predator exclosure than on controls $(16.1 \%$ versus

Table 8. Summary of qualitative direct effects on biomass produced by experimental perturbation at the peak values. $\mathrm{M}$ refers to manipulated level with $\mathrm{M}^{+}$indicating the experimental addition, $\mathrm{M}^{-}$the experimental removal. $+=$increase, $-=$decrease, $0=$ no change.

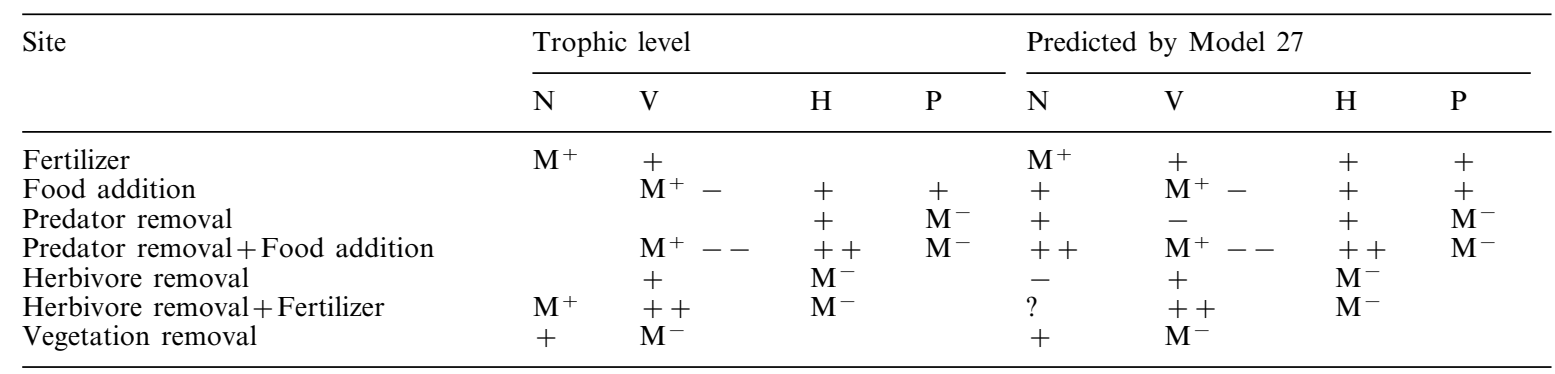


$12.0 \%, P<0.05)$ but birch did not $(21.1 \%$ versus $23.9 \%$ ) (Table 4). Thus, in general we did not detect indirect top-down changes in either willow or birch biomass resulting from the higher herbivore numbers on this predator exclosure treatment.

The double indirect effect would be detected at the soil nutrient level. In 1995 soil nitrate nitrogen was $0.37 \mathrm{ppm}$ on the predator exclosure and $0.18 \mathrm{ppm}$ on controls, the difference being not significant.

\section{(4) Food addition and predator exclosure}

Indirect effects would be seen at the soil nutrient level. In the exclosure in 1995 soil nitrate nitrogen was $0.85 \mathrm{ppm}$, that on controls $0.33 \mathrm{ppm}$. No significant differences were detected.

\section{(5) Hare exclosure}

In 1996 soil nitrate nitrogen in 100 samples averaged 8.34 ( $\pm 0.4595 \%$ C.L.) ppm, while 100 samples immediately adjacent outside the exclosure averaged 5.2 $( \pm 0.3695 \%$ C.L. $)$ ppm, a difference significant at $P<0.0001$. A similar difference was detected in 1995 $(P<0.02)$. Therefore, the indirect effect of herbivores is to increase the uptake of nutrients into the vegetation to compensate for herbivory and so reduce the pool of nutrients in the soil. This result is due to a productivity response at the plant level.

\section{Discussion}

\section{Direct effects}

Table 8 summarizes the significant direct effects on biomass derived from each of the experiments. Each of the removal experiments produced an increase in biomass at the level below. The two addition experiments (nutrients on fertilizer grid, food for herbivores on food addition grid) produced an increase in the level above, and for food addition a decrease in level below. Because we were unable for practical reasons to increase the herbivores directly we could not test the $H \rightarrow P$ direct interaction. However, we can see from the indirect effect of food addition (Table 9) that there is a positive link from $H$ to $P$. Therefore, putting these interactions together we see the pattern

$N \leftrightarrow V \leftrightarrow H \leftrightarrow P$

and this is the "pure reciprocal" combination 27 in Table 1. The predictions of this model are provided in Table 8 for comparison with our results. 


\section{Indirect effects}

The above conclusion stems only from direct effects. When we consider only indirect effects, the conclusions are more complex. Table 9 summarizes the indirect effects on biomass from each experiment. The nutrient addition produced small but positive effects at the peak of the cycle, but over the whole cycle these effects were not evident. In contrast, top-down indirect effects were not detectable despite direct effects being strong. One top-down effect (herbivore removal on soil nutrients, experiment 5) even went in the direction opposite to that predicted, namely that there was an increase in nutrient pool instead of a decrease. This result is most likely due to the fact that the shrubs responded to herbivory by growing more (see below) as well as having decreased biomass. More growth, therefore, reduces the nutrient pool relative to areas with no herbivory (i.e, where herbivores are removed the nutrient pool increases). This result from the nutrient pool illustrates that predictions from simple change of biomass are different from those due to change in productivity.

Table 9 presents the models for which the results of each experiment are consistent. Our findings do not match any model completely if we take them strictly at face value because of the anomalous result from experiment (5) of an increase in nutrient pool when herbivores are removed as discussed above. The results in Table 9 are most consistent with the predictions of model 23 (Table 9) where there is little indirect topdown effect at the soil level. However, if we recognize that the nutrient result in experiment (5) was due to a productivity response of the vegetation and that there was in fact a top-down effect as seen from the vegetation removal experiment (7) (Table 8) then models 27 and 21 are as consistent as model 23 .

In general, both top-down and bottom-up indirect effects tend to attenuate rapidly so that there is little effect of perturbations at the far end of the food chain.

\section{Top-down versus bottom-up}

Can we draw conclusions on the relative strengths of top-down and bottom-up effects? The double perturbation experiments provide some clues. In 1991 birch on the fertilized grids (with hares) had a higher growth rate than that on the fertilized hare exclosure by a factor of 1.23 , but willow showed no difference in growth rate. This result suggests that the greater hare browsing on birch stimulated growth but the lesser browsing on willow did not. In contrast, willow on the unfertilized hare exclosure had a much lower growth rate than that on the fertilized exclosure (by a factor of 0.62 ). This result suggests that in willow fertilizer produced a stronger stimulation for growth than did hare browsing.
The net effect of browsing and growth on fertilizer grids produced a decline of willow twig biomass by a factor of 0.78 , whereas on control areas willow biomass barely declined at all (factor of 0.98). For birch browsing was much more severe so that in both fertilizer and control areas net biomass declined to 0.49 and 0.16 of that a year earlier. Thus, fertilizer may have increased growth rate but it also increased herbivory to an even greater extent so that biomass declined. Therefore, topdown effects outweighed bottom-up effects at the vegetation level in winter. This is contrary to the summer food situation where herbivory had virtually no effect on vegetation compared with that of fertilizer addition (John and Turkington 1995).

In the winter of 1991-1992 predators were having their most marked effect. Herbivore biomass on the food addition site (with predators) declined from spring 1991 to spring 1992 at an instantaneous rate of -1.137 compared with a decline of herbivore biomass of 0.062 on the double food addition plus predator exclosure. The greater rate of decline of herbivores on the food addition is, therefore, due to the presence of predators. Furthermore, the rate of decline on control grids in the presence of predators but without the extra hare food $(-0.667)$ was actually less than that on the food addition in the presence of food. Therefore, predation was the dominant process and food had no detectable effect in mitigating the decline in herbivores. Thus, top-down effects dominated bottom-up effects at the herbivore level.

\section{Productivity and biomass responses}

To what extent was there a productivity response to top-down effects, and could it compensate for biomass loss? The hare exclosure, control areas, predator exclosure, food addition and the double food and predator exclosure produced a sequence of increasing herbivory in the peak winter of 1990-1991. Subsequent growth of both willow and birch was positively related to browsing intensity in the previous winter (regression for both species combined, \%growth $=13.03+0.216 \%$ browse, $n=9, P<0.005)$. We could not detect any effect in soil nitrogen from the additional hare inputs through feces and urine. Therefore, at least at the vegetation level, winter food plants responded to top-down effects by an increased growth rate. The time scale of our experiments was not sufficient to detect the indirect effects on nutrient cycling resulting from selective browsing on angiosperms relative to conifers that Pastor et al. (1993) observed for moose in their 40-year experiments.

In no case, however, did this productivity response compensate entirely for herbivory, its compensatory effect was relatively minor. However, at the next level down, soil nutrient content declined under conditions of herbivory (experiment (5)) contrary to the predicted 
increase, a result consistent with the higher productivity of plants that experience herbivory drawing down the nutrient pool.

\section{General models of trophic level interactions}

We started this analysis of models and their predictions by assuming parsimoniously simple linear, first-order interactions. We recognize that many other models could be proposed including non-linear interactions (e.g. saturating functional responses). This is perhaps the next step but we expect that models with saturating functional responses could lead to basically similar predictions. However, more complex linkages (e.g. top predators eating more than one level) are difficult to predict (Neill 1988, Polis and Strong 1996), so we suggest starting with experimental tests of simple models and see how they stand up (Hairston and Hairston 1997).

Although we cannot assign individual models to particular ecosystems we can speculate on the classes of models that may be applicable in different ecosystems. It is possible, for example, that models with mainly left arrows (largely top down effects, e.g. 5-8, 22, 24, 26) may apply to aquatic systems (Menge and Sutherland 1976, Estes et al. 1977, Simenstad et al. 1978, Paine 1980, McQueen et al. 1986, Power 1990, Menge 1992, 1995, Carpenter and Kitchell 1993, Rosemund et al. 1993, Wootton 1994a). Indirect effects are well-known in aquatic and marine systems and it is possible that they attenuate less rapidly than they seem to do in our terrestrial system (Schoener 1993, Wootton 1993, 1994b, Menge 1997).

In tropical savannas such as the Serengeti (Sinclair 1975, McNaughton 1985, Sinclair and Arcese 1995) and temperate grasslands (Huntly 1991) where herbivores dominate models with arrows leading from the herbivores could apply (e.g. 9-13, 21, 23-24, 26). For insect-parasitoid or insect-predator systems where the predator level could dominate (Lawton and Strong 1981, Strong et al. 1984, Price et al. 1990, Gomez and Zamora 1994, Spiller and Schoener 1994, Floyd 1996, Moran and Hurd 1998) models 5-8, 22, 24, 26 might apply. Alternatively, both bottom-up and top-down (dilution) effects at the herbivore level could operate in insect herbivores (models 15-18, 20)(Hairston et al. 1960, McQueen et al. 1986, Pace and Funke 1991, Harrison and Cappuccino 1995). In contrast, in temperate and subarctic systems where vegetation and herbivores dominate (Oksanen et al. 1981, Oksanen 1990, Fretwell 1987, Moen et al. 1993, Marquis and Whelan 1994, Krebs et al. 1995) models 9-17 could apply. Tropical forests, where vegetation dominates (Connell 1978, 1983, Lodge et al. 1994), could be represented by models 14-17, 21-22, 24-25. Nutrient-poor sclerophyll forests such as those of Australia have strong bottom-up effects (Braithwaite et al. 1983, Braithwaite 1996) and would be represented by largely right arrow models such as $1-4,16,20-23,25$. The most general of the models is number 27 , the pure reciprocal model, because it could represent many if not all ecosystems. Density manipulation experiments in these different ecosystems is the most effective way of determining the generality of these top-down and bottom-up models (Dwyer 1995).

We employed both removal and addition experiments. Removal experiments are the more powerful, because to analyze the effect of a factor it must be removed. Addition experiments are not the reverse of removals (Royama 1977), but they are necessary in this context to determine the presence of right-arrow regulatory effects. We also found that the double perturbation experiments where both addition and removal were applied provided valuable insights as to the relative strengths of simultaneous top-down and bottom-up effects.

\section{Conclusion}

We conducted either removal or addition experiments on each trophic level of the boreal forest ecosystem at Kluane, Yukon. We measured the response of other levels in terms of biomass, productivity and activity. The direct effects of the perturbations on the next trophic level are consistent with the pure reciprocal model. The two experiments that produced simultaneous bottom-up and top-down effects indicated that top-down was the stronger direct effect. In contrast to direct effects, indirect effects although detectable, were relatively weak at all levels. The experiments suggest, therefore, strong reciprocal direct effects and weak, highly attenuated indirect effects at all trophic levels in the Kluane boreal forest ecosystem. This result differs from the stronger indirect effects seen in aquatic systems (Kerfoot and Sih 1987, Neill 1988).

There are many possible models that may represent a particular ecosystem, and it is not immediately obvious which is the best representation. Models should be tested in different biomes through manipulation experiments to see whether some subset of the models is more likely in nature. In particular, we need to determine the degree to which reciprocal effects between levels (double arrows) occur relative to self-limiting effects and one-way effects in different ecosystems.

Acknowledgements - Many people have helped us carry out the field experiments, too many to mention, but we thank them all. In particular we thank Cathy Doyle, Frank Doyle, Liz Hofer, Vilis Nams, Mark O’Donoghue, Sabine Schweiger. We thank P. Abrams for helpful discussion, and Kjell Danell and the Swedish Agricultural University, Umeå, for travel funds to Sweden by A.R.E.S. and J.M.F. This work has been funded by a Collaborative Special Projects grant from the Natural Sciences and Engineering Research Council of Canada, and the Northern Studies Training Programme for students. This is paper 97 of the Kluane Boreal Forest Ecosystem project. 


\section{References}

Arditi, R. and Ginsburg, L. R. 1989. Coupling in predatorprey dynamics: ratio-dependence. - J. Theor. Biol. 139: 311-326.

Arditi, R., Ginsburg, L. R. and Akçakaya, H. R. 1991. Variation in plankton densities among lakes: a case for ration-dependent predation models. - Am. Nat. 138: $1287-1296$.

Atlegrim, O. 1989. Exclusion of birds from bilberry stands: impact on insect larval density and damage to the bilberry. - Oecologia 79: 136-139.

Batzli, G. O., White, R. G., Maclean, S. F. et al. 1980. The herbivore based trophic system. - In: Brown, J., Miller, P. C., Tiezen, L. L. and Bunnell, F. L. (eds), An arctic ecosystem: the coastal tundra at Barrow, Alaska. Dowden, Hutchinson and Ross, Stroudsburg, PA, pp. 335-410.

Benndorf, J. and Horn, W. 1985. Theoretical considerations on the relative importance of food limitation and predation in structuring zooplankton communities. - In: Lampert, W. (ed.), Food limitation and the structure of zooplankton communities. E. Schweizerbart'sche Verlagsbuchhandlung, Stuttgart, pp. 383-396.

Billick, I. and Case, T. J. 1994. Higher order interactions in ecological communities: what are they and how can they be detected? - Ecology 75: 1529-1543.

Boonstra, R., Hik, D., Singleton, G. R. and Tinnikov, A. 1998. The impact of predator-induced stress on the snowshoe hare cycle. - Ecol. Monogr. 68: 371-394.

Boutin, S., Krebs, C. J., Boonstra, R. et al. 1995. Population changes of the vertebrate community during a snowshoe hare cycle in Canada's boreal forest. - Oikos 74: 69-80.

Braithwaite, L. W. 1996. Conservation of arboreal herbivores: the Australian scene. - Aust. J. Ecol. 21: 21-30.

Braithwaite, L. W., Dudzinski, M. L. and Turner, J. 1983. Studies of the arboreal eucalypt forests being harvested for woodpulp at Eden, New South Wales. II. Relationship between the fauna density, richness and diversity and measured variables of habitat. - Aust. Wildl. Res. 10: $231-$ 247.

Carpenter, S. R. and Kitchell, J. F. 1987. The temporal scale of variance in limnetic primary production. - Am. Nat. 129: $417-433$

Carpenter, S. R. and Kitchell, J. F. 1988. Consumer control of lake productivity. - BioScience 38: 764-769.

Carpenter, S. R. and Kitchell, J. F. (eds) 1993. The trophic cascade in lakes. - Cambridge Univ. Press, Cambridge.

Carpenter, S. R., Kitchell, J. F. and Hodgson, J. R. 1985 Cascading trophic interactions and lake productivity. BioScience 35: 634-639.

Caughley, G. 1976. Plant-herbivore systems. - In: May, R. M. (ed.), Theoretical ecology. Saunders, Philadelphia, pp. 94113.

Caughley, G. and Lawton, J. H. 1981. Plant-herbivore systems. - In: May, R. M. (ed.), Theoretical ecology, 2nd ed. Blackwell, Oxford, pp. 132-166.

Caughley, G. and Gunn, A. 1993. Dynamics of large herbivores in deserts: kangaroos and caribou. - Oikos 67: $47-55$.

Chitty, D. 1960. Population processes in the vole and their relevance to general theory. - Can. J. Zool. 38: 99-113.

Coe, M. J., Cumming, D. H. and Phillipson, J. 1976. Biomass and production of large African herbivores in relation to rainfall and primary production. - Oecologia 22: 314-354

Connell, J. H. 1978. Diversity in tropical rainforests and coral reefs. - Science 199: 1302-1310.

Connell, J. H. 1983. On the prevalence and relative importance of interspecific competition: evidence from field experiments. - Am. Nat. 122: 661-696.

Estes, J. A. and Duggins, D. O. 1995. Sea otters and kelp forests in Alaska: generality and variation in a community ecological paradigm. - Ecol. Monogr. 65: 75-100.
Estes, J. A., Smith, N. S. and Palmisano, J. F. 1977. Sea otter predation and community organisation in the Western Aleutian Islands, Alaska. - Ecology 59: 822-833.

Estes, J. A., Duggins, D. O. and Rathbun, G. B. 1989. The ecology of extinctions in kelp forest communities. - Conserv. Biol. 3: 252-264

Dungan, M. L. 1987. Indirect mutualism: complementary effects of grazing and predation in a rocky intertidal community. - In: Kerfoot, W. C. and Sih, A. (eds), Predation: direct and indirect impacts on aquatic communities. Univ. Press of New England, Hanover, NH, pp. 188-200.

Dwyer, G. 1995. Simple models and complex interactions. In: Cappuccino, N. and Price, P. W. (eds), Population dynamics: new approaches and synthesis. Academic Press, New York, pp. 209-227.

Floyd, T. 1996. Top-down impacts on creosotebush herbivores in a spatially and temporally complex environment. Ecology 77: 1544-1555.

Fretwell, S. D. 1977. The regulation of plant communities by food chains exploiting them. - Persp. Biol. Med. 20: $169-185$.

Fretwell, S. D. 1987. Food chain dynamics: the central theory of ecology? - Oikos 50: 291-301.

Gomez, J. M. and Zamora, R. 1994. Top-down effects in a tritrophic system: parasitoids enhance plant fitness. - Ecology 75 : $1023-1030$.

Hairston, N. G. and Hairston, N. G. 1997. Does food web complexity eliminate trophic-level dynamics? - Am. Nat. 149: $1001-1007$.

Hairston, N. G., Smith, F. E. and Slobodkin, L. B. 1960 Community structure, population control and competition - Am. Nat. 94: 421-425.

Hanski, I. 1991. The functional response of predators: worries about scale. - Trends Ecol. Evol. 6: 141-142.

Harrison, S. and Cappuccino, N. 1995. Using density-manipulation experiments to study population regulation. - In: Cappuccino, N. and Price, P. W. (eds), Population dynamics: new approaches and synthesis. Academic Press, New York, pp. 131-148

Hawkins, B. A. 1992. Parasitoid-host food web and donor control. - Oikos 65: 159-162

Holt, R. D. 1977. Predation, apparent competition, and the structure of prey communities. - Theor. Popul. Biol. 12: $197-229$.

Hunter, M. D. and Price, P. W. 1992. Playing chutes and ladders: bottom-up and top-down forces in natural communities. - Ecology 73: 724-732

Huntly, N. 1991. Herbivores and the dynamics of communities and ecosytems. - Annu. Rev. Ecol. Syst. 22: 477-503.

John, E. and Turkington, R. 1995. Herbaceous vegetation in the understory of the boreal forest: does nutrient supply or snowshoe hare herbivory regulate species composition and abundance? - J. Ecol. 83: 581-590.

Kerfoot, W. C. and Sih, A. (eds) 1987 Predation: direct and indirect impacts on aquatic communities. - Univ. Press of New England, Hanover, NH.

Krebs, C. J. 1978. A review of the Chitty hypothesis of population regulation. - Can. J. Zool. 56: 2463-2480.

Krebs, C. J., Boonstra, R., Boutin, S. et al. 1992. What drives the snowshoe hare cycle in Canada's Yukon? - In: McCullough, D. M. and Barrett, R. (eds), Wildlife 2001: populations. Elsevier, London, pp. 886-896.

Krebs, C. J., Boutin, S., Boonstra, R. et al. 1995. Impact of food and predation on the snowshoe hare cycle. - Science. 269: $1112-1115$.

Lampert, W. (ed.) 1985. Food limitation and the structure of zooplankton communities. - E. Schweizerbart'sche Verlagsbuchhandlung, Stuttgart.

Lawton, J. H. and Strong, D. R. 1981. Community patterns and competition in folivorous insects. - Am. Nat. 118: 317-338.

Leibold, M. A. 1996. A graphical model of keystone predators in food webs: trophic regulation of abundance, incidence, and diversity patterns in communities. - Am. Nat. 147: $784-812$. 
Lodge, D. J., McDowell, W. H. and McSwiney, C. P. 1994. The importance of nutrient pulses in tropical forests. - Trends Ecol. Evol. 9: 384-387.

Marquis, R. J. and Whelan, C. J. 1994. Insectivorious birds increase growth of white oak through consumption of leaf-chewing insects. - Ecology 75: 2007-2014.

McLaren, B. E. and Peterson, R. O. 1994. Wolves, moose and tree rings on Isle Royale. - Science 266: 1555-1557.

McNaughton, S. J. 1985. Ecology of a grazing ecosystem: the Serengeti. - Ecol. Monogr. 55: 259-294.

McNaughton, S. J., Osterheld, M., Frank, D. A. and Williams, K. J. 1989. Ecosystem level patterns of primary productivity and herbivory in terrestrial habitats. - Nature 341: 142-144.

McQueen, D. G., Post, J. R. and Mills, E. L. 1986. Trophic relationships in freshwater pelagic ecosystems. - Can. J. Fish. Aquat. Sci. 43: 1571-1581.

McQueen, D. G., Johannes, M. R. S., Post, J. R. et al. 1989 Bottom-up and top-down impacts on freshwater pelagic community structure. - Ecol. Monogr. 59: 289-309.

Menge, B. A. 1992. Community regulation: under what conditions are bottom-up factors important on rocky shores? Ecology 73: 755-765.

Menge, B. A. 1995. Indirect effects in marine rocky intertidal interaction webs: patterns and importance. - Ecol. Monogr. 65: $21-74$.

Menge, B. A. 1997. Detection of direct versus indirect effects: were experiments long enough? - Am. Nat. 149: 801-823.

Menge, B. A. and Sutherland, J. P. 1976. Species diversity gradients: synthesis of the roles of predation, competition and temporal heterogeneity. - Am. Nat. 110: 351-369.

Moen, J. and Oksanen, L. 1991. Ecosystem trends. - Nature 353: 510.

Moen, J., Gardfjell, H., Oksanen, L. et al. 1993. Grazing by food-limited microtine rodents on a productive experimental plant community: does the "green desert" exist? - Oikos 68: 401-413.

Moran, M. D. and Hurd, L. E. 1998. A trophic cascade in a diverse arthropod community caused by a generalist arthropod predator. - Oecologia 113: 126-132.

Neill, W. E. 1988. Complex interactions in oligotrphic lake food webs: responses to nutrient enrichment. - In: Carpenter, S. R. (ed.), Complex interactions in lake communities. Springer-Verlag, New York, pp. 31-44

Oksanen, L. 1988. Ecosystem organization: mutualism and cybernetics or plain Darwinian struggle for existence? - Am. Nat. 131: 424-444

Oksanen, L. 1990. Predation, herbivory, and plant strategies along gradients of primary productivity. - In: Tilman, D. and Grace, J. (eds), Perspectives on plant competition. Academic Press, New York, pp. 445-474.

Oksanen, L., Fretwell, S. D., Arruda, J. and Niemelä, P. 1981 Exploitation ecosystems in gradients of primary productivity. - Am. Nat. 118: 240-261.

Oksanen, T. 1990. Exploitation ecosystems in heterogeneous habitat complexes. - Evol. Ecol. 4: 220-234.

Pace, M. L. and Funke, E. 1991. Regulation of planktonic microbial communities by nutrients and herbivores. - Ecology 72: 904-914.

Paine, R. T. 1980. Food webs: linkage, interaction strength and community infrastructure. - J. Anim. Ecol. 49: 667-685.

Pastor, J., Dewey, B., Naiman, R. J. et al. 1993. Moose browsing and soil fertility in the boreal forests of Isle Royal National Park. - Ecology 74: 467-480.

Persson, L., Andersson, G., Hamrin, S. F. and Johansson, L. 1988. Predator regulation and primary productivity along the productivity gradient of temperate lake ecosystems. - In: Carpenter, S. R. (ed.), Complex interactions in lake communities. Springer, Berlin, pp. 45-65.

Persson, L., Diehl, S., Johansson, L. et al. 1992. Trophic interactions in temperate lakes-a test of food chain theory. - Am. Nat. 140: 59-84

Polis, G. A. and Strong, D. R. 1996. Food web complexity and community dynamics. - Am. Nat. 147: 813-846.
Power, M. E. 1984. Depth distributions of armoured catfish: predator-induced resource avoidance? - Ecology 65: 523528

Power, M. E. 1990. Effects of fish in river food webs. - Science 250: $811-814$

Power, M. E. 1992. Top-down and bottom-up forces in food webs: do plants have primacy? - Ecology 73: 733-746.

Price, P. W., Cobb, N., Craig, T. P. et al. 1990. Insect herbivore population dynamics on trees and shrubs: new approaches relevant to latent and eruptive species and life table development. - In: Bernays, E. A. (ed.), Insect-plant interactions. Vol. 2. CRC, Boca Raton, FL, pp. 1-38.

Rosemund, A. D., Mulholland, P. J. and Elwood, J. W. 1993. Top-down and bottom-up control of stream periphyton: effects of nutrients and herbivores. - Ecology 74: 1264 1280.

Royama, T. 1977. Population persistence and density dependence. - Ecol. Monogr. 47: 1-35.

Schoener, T. W. 1993. On the relative importance of direct versus indirect effects in ecological communities. - In: Kawanabe, H., Cohen, J. E. and Iwasaki, K. (eds), Mutualism and community organization: behavioral, theoretical and food-web approaches. Oxford Univ. Press, New York, pp. $365-411$.

Simenstad, C. A., Estes, J. A. and Kenyon, K. A. 1978. Aleuts, sea otters and alternate stable state communities. - Science 200: 403-411.

Sinclair, A. R. E. 1975. The resource limitation of trophic levels in tropical grassland communities. - J. Anim. Ecol. 44: 497-520.

Sinclair, A. R. E. and Arcese, P. (eds) 1995. Serengeti II: dynamics, management and conservation of an ecosystem. - Univ. of Chicago Press, Chicago.

Sinclair, A. R. E., Dublin, H. and Borner, M. 1985. Population regulation of Serengeti wildebeest: a test of the food hypothesis. - Oecologia 65: 266-268.

Spencer, C. N. and King, D. L. 1984. Role of fish in regulation of plant and animal communities in eutrophic ponds. - Can. J. Fish. Aquat. Sci. 41: 1851-1855.

Spiller, D. A. and Schoener, T. W. 1994. Effects of top and intermediate predators in a terrestrial food web. - Ecology 75: $182-196$.

Strong, D. R. 1992. Are trophic cascades all wet? Differentiation and donor-control in speciose ecosystems. - Ecology 73: $747-754$

Strong, D. R., Simberloff, D., Abele, L. G. and Thistle, A. B. (eds) 1984. Ecological communities: conceptual issues and the evidence. - Princeton Univ. Press, Princeton, NJ.

Turkington, R., John, E., Krebs, C. J. et al. 1998. The effects of NPK fertilization for nine years on the vegetation of the boreal forest in northwestern Canada. - J. Veg. Sci. 9: $333-346$

White, T. C. R. 1978. The importance of a relative shortage of food in animal ecology. - Oecologia 3: 71-86.

White, T. C. R. 1984. The abundance of invertebrate herbivores in relation to the availability of nitrogen in stressed food plants. - Oecologia 63: 90-105.

White, T. C. R. 1993. The inadequate environment: nitrogen and the abundance of animals. - Springer-Verlag, Berlin.

Wootton, J. T. 1993. Indirect effects and habitat use in an intertidal community: interaction chains and interaction modifications. - Am. Nat. 141: 71-89.

Wootton, J. T. 1994a. Predicting direct and indirect effects: an integrated approach using experiments and path analysis. Ecology 75: 151-165.

Wootton, J. T. 1994b. The nature and consequences of indirect effects in ecological communities. - Annu. Rev. Ecol. Syst. 25: $443-466$

Wootton, J. T. 1994c. Putting the pieces together: testing the independence of interactions among organisms. - Ecology 75: $1544-1551$

Yodzis, P. 1988. The indeterminancy of ecological interactions as perceived through perturbation experiments. - Ecology 69: $508-515$. 